\title{
Shear Velocity in the Lower Mantle From Explosion Data
}

\author{
ROBERT S. HART \\ Seismological Laboratory, California Institute of Technology, Pasadena, California 91125
}

\begin{abstract}
A new technique utilizing theoretical wave forms has been developed to determine precise shear wave travel times. This technique was applied to long-period World-Wide Standard Seismograph Network and Canadian network seismograms of five large nuclear explosions to obtain a surface focus shear wave data set containing about 100 travel times for distances greater than $30^{\circ}$. Very little scatter is present in the data from Novaya Zemlya and the Nevada test site, and so a reliable inversion to a lower mantle velocity structure is permitted. This velocity model, based on the 59 travel tımes from Novaya Zemlya, has significantly more structure than earlier models. The model, SI, has proved to be appropriate for free oscillations as well as for travel times. This model should be useful in studying both lateral inhomogeneities and the mineralogical composition of the earth's mantle.
\end{abstract}

\section{INTRODUCTION}

The shear velocity structure in the lower mantle is signifcantly less well determined than the compressional velocity structure in the same region. This uncertainty occurs primarily because the $S$ wave is not the first arrival phase, and owing to $P$-SV coupling, the actual onset of the shear pulse is usually obscured by various precursor arrivals. A new technique has been devised with which it is possible to minimize greatly the errors in determining shear wave travel times and hence in accurately defining the shear velocity structure. This technique utilizes the theoretically determined wave form of the shear wave and its precursors to compute the true arrival time of the phase. Since explosions have a relatively simple source function, they are particularly appropriate for application of this method. In addition, the origin time, depth, and epicenter of large nuclear explosions are generally known to high accuracy, especially for the blasts in Nevada and the Aleutians. Even the Soviet blasts, for present purposes, have fairly well determined source parameters.

\section{TECHNIQUE}

Other investigators [Kogan, 1960; Ibrahim and Nuttli, 1967; Nuttli, 1969] have previously used explosion data in attempting to improve shear wave travel times. Ibrahim and Nuttli employed two techniques, particle motion analysis and determination of the product of the vertical and horizontal components of motion, in order to eliminate the effects of compressional precursors. While these techniques represent an improvement over simple visual identification of arrival times, neither method is entirely satisfactory, since both rely on the initial portions of the wave form, which are generally distorted by the precursor arrivals, particularly by the $S p$ phase. The $S p$ phase is the major precursor to the shear wave and arises from $S V-P$ conversion at the Mohorovicic discontinuity below the observing station. In addition, any departure from radial layering in the earth introduces further errors into these analysis methods. Our technique, described in more detail below, is not sensitive to such symmetry deviations, and since it relies more heavily on the later portions of the wave form, it is essentially insensitive to precursor contamination.

Following a suggestion by D. V. Helmberger (personal communication, 1973), synthetic seismograms of $p S$, the dominant teleseismic shear energy from an explosion (a theoretically pure compressional source), were generated by using the source function proposed by Helmberger and Harkrider

Copyright (C) 1975 by the American Geophysical Union.
[1972]. This source function has a laster rise time than the Haskell [1967] source and has proved to be very accurate in reproducing the $P$ waves from nuclear explosions. This function therefore was considered to be the most appropriate source representation for this study. The resulting synthetics were then compared to actual long-period World-Wide Standard Seismograph Network (WWSSN) records of events in Nevada, in the Aleutians, and at the Soviet test site on Novaya Zemlya. Figure 1 shows this comparison for several records as well as for the Helmberger-Harkrider source-time function. The $S p$ precursor is included in the second synthetic wave form (Figure $1 b$ ) and is also obvious in the actual seismograms. The correlation between observed records and synthetics is very good.

Our technique, then, is straightforward. The wave form and, in particular, the width of the first peak are essentially constant, at least for ranges greater than about $30^{\circ}$. The arrival time of this first peak is measured on the seismogram, and a correction of $3.7 \mathrm{~s}$, computed from the synthetic wave form, is applied to the peak arrival time to compute the actual onset time of the $p S$ phase. Consideration of the required polarity of the wave form on each component permits an unambiguous identification of the correct peak or trough. The arrival times are then corrected in the standard manner for ellipticity [Bul-

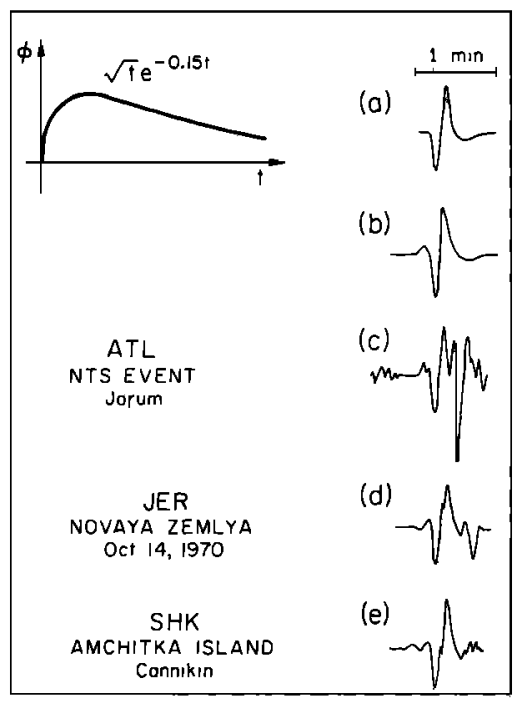

Fig. 1. The time function of the Helmberger and Harkrider [1972] explosion source (inset at upper left) and synthetic seismograms for $(a)$ the shear wave and $(b)$ the shear wave with precursor; $(c, d, e)$ three typical observed records from the three source regions. 
TABLE 1. Observed Travel Times

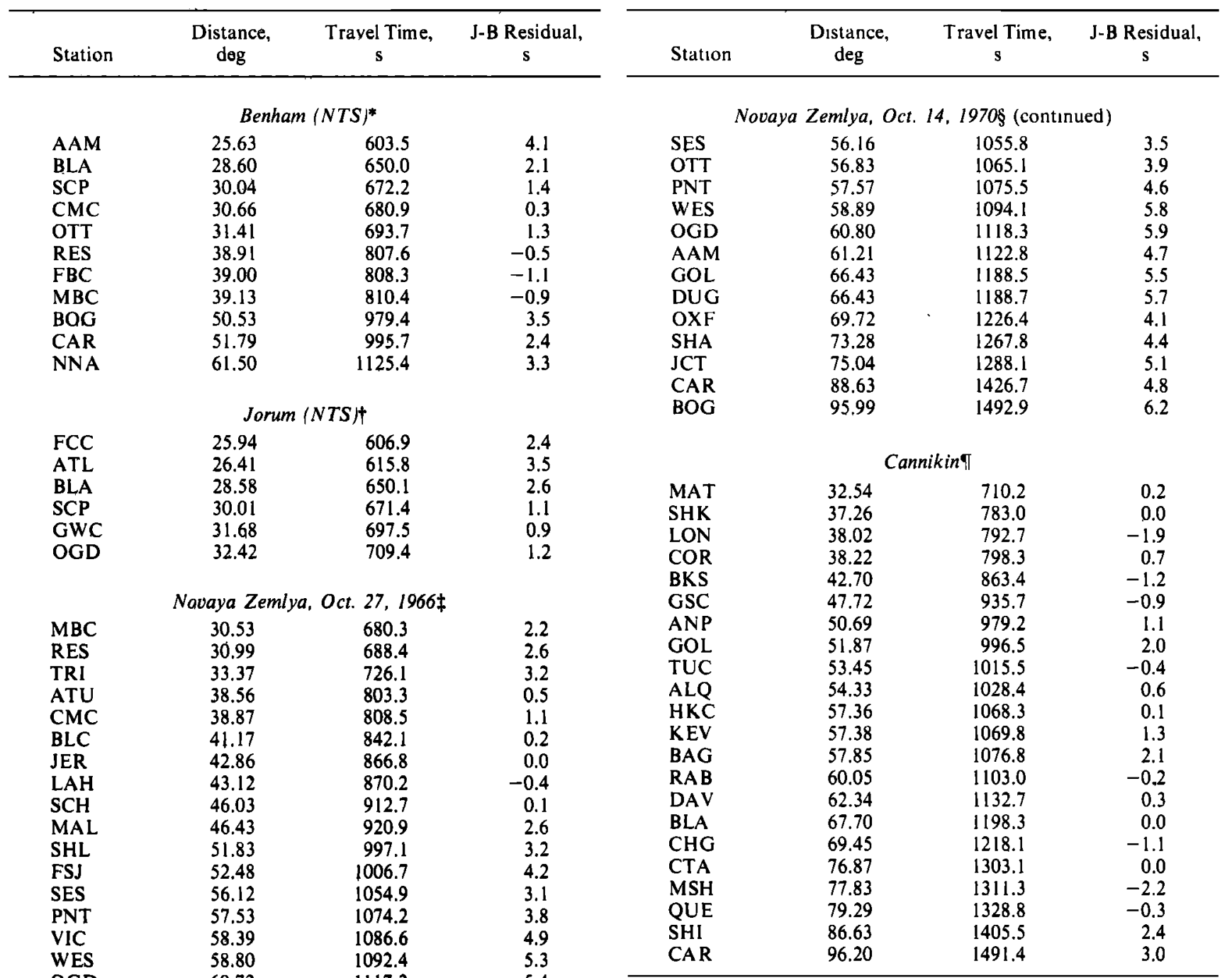

$\begin{array}{lll}\mathrm{BAG} & 67.58 & 1202.1\end{array}$

*December 19, 1968; $06 \mathrm{~h} 30 \mathrm{~m} 00.0 \mathrm{~s} ; 37.23^{\circ} \mathrm{N}, 116.47^{\circ} \mathrm{W}$. $\dagger$ September 16,$1969 ; 14 \mathrm{~h} 30 \mathrm{~m} 00.0 \mathrm{~s} ; 37.31^{\circ} \mathrm{N}, 116.46^{\circ} \mathrm{W}$. $\ddagger 05 \mathrm{~h} 58 \mathrm{~m} 00.4 \mathrm{~s} ; 73.38^{\circ} \mathrm{N}, 54.62^{\circ} \mathrm{E}$. $\$ 05 \mathrm{~h} 59 \mathrm{~m} 59.8 \mathrm{~s} ; 73.35^{\circ} \mathrm{N}, 54.94^{\circ} \mathrm{E}$.

TNovember 6,$1971 ; 22 \mathrm{~h} 00 \mathrm{~m} 00.1 \mathrm{~s} ; 51.5^{\circ} \mathrm{N}, 179.1^{\circ} \mathrm{E}$.

Novaya Zemlya, Oct. 14, 1970\$

$\begin{array}{lrrr}\text { MBC } & 30.57 & 682.0 & 3.1 \\ \text { RES } & 31.04 & 690.4 & 3.8 \\ \text { VAL } & 34.23 & 739.4 & 3.1 \\ \text { IST } & 34.68 & 744.1 & 0.9 \\ \text { TAB } & 35.61 & 758.7 & 1.0 \\ \text { FBC } & 38.11 & 795.5 & -0.5 \\ \text { KBL } & 39.62 & 818.2 & -0.6 \\ \text { COL } & 41.18 & 842.7 & 0.6 \\ \text { BCL } & 41.23 & 842.4 & -0.4 \\ \text { JER } & 42.88 & 867.1 & 0.0 \\ \text { QUE } & 43.68 & 878.0 & -0.8 \\ \text { SHI } & 43.80 & 881.0 & 0.5 \\ \text { YKC } & 44.25 & 888.1 & 1.1 \\ \text { EIL } & 45.10 & 901.3 & 2.0 \\ \text { HLW } & 45.26 & 902.9 & 1.3 \\ \text { SCH } & 46.12 & 915.2 & 1.3 \\ \text { NDI } & 46.24 & 916.5 & 0.9 \\ \text { FCC } & 46.49 & 919.6 & 0.4 \\ \text { MAL } & 46.51 & 919.6 & 0.1 \\ \text { GWC } & 47.67 & 938.3 & 2.4 \\ \text { FFC } & 51.24 & 989.2 & 3.5 \\ \text { SHL } & 51.75 & 997.6 & 4.9 \\ \text { FSJ } & 52.51 & 1008.1 & 5.0 \\ \text { EDM } & 53.47 & 1019.5 & 3.3 \\ \text { MAT } & 53.50 & 1019.9 & 3.3 \\ \text { HAL } & 55.11 & 1041.6 & 3.3 \\ \text { POO } & 55.86 & 1053.2 & 4.9 \\ & & & \end{array}$

len, 1937] and for the elevation of the station and source. Last, a small time correction removes the initial compressional path contribution to the $p S$ travel time, and we obtain a surface focus $S$ travel time. This last correction can be computed very accurately for the Nevada test site (NTS) events and for the Cannikin test in the Aleutians by using the near-field structures determined by aftershock studies [Hamilton and Healy. 1969; Stauder. 1971; Engdahl, 1972]. For those explosions in Novaya Zemlya this correction was estimated by assuming a reasonable mean velocity and depth of burial. Errors in these estimates do not cause significant errors in the overall travel times.

\section{DATA}

Five nuclear explosions were used in this study: two NTS events, Benham and Jorum; the Cannikin event; and two Soviet events on Novaya Zemlya, the first on October 27, 1966, and the other on October 14, 1970. These events were selected because they generated clearly resolvable shear waves at distances greater than $30^{\circ}$. Seismograms from WWSSN and Canadian network stations were examined for identifiable $p S$ arrivals from all five events. Ninety-six travel times were ob- 
tained at distances ranging from $25.63^{\circ}$ to $95.99^{\circ}$. Most of the data are for distances of less than $75.0^{\circ}$.

In order to determine travel times and then to invert to a velocity structure it is necessary to obtain accurate locations and origin times. For the American tests this is a simple matter, but for the Soviet blasts no official announcement is released, and the available computed parameters were not completely trustworthy. The geographical location of the Novaya Zemlya test site is surrounded by stations at a wide range of distances and azimuths. Thus since the depth of an explosion is tightly constrained, the computed epicentral locations of the explosions will vary only by a few kilometers from the locations in any realistic travel time model. Such small shifts will not produce resolvable differences in teleseismic travel times. However, the computed origin time of an event depends critically upon the model employed. The two Soviet tests were relocated by using four models: the Jeffreys-Bullen (J-B) tables, the 1968 tables [Herrin et al., 1968], the gross earth mode] B1 [Jordan and Anderson, 1974], and the gross earth model UTD124B [Dziewonski and Gilbert, 1972]. Since it was believed that the explosions were detonated on the minute or as close as possible to that time, that criterion was used to select the B1 solution. This solution also seemed to be the most likely on the basis of the island terrain of the test site. The resulting source parameters and the corresponding International Seismological Centre (ISC) determinations are as follows:

October 27, 1966

B1 $\quad 05 \mathrm{~h} 58 \mathrm{~m} 00.4 \mathrm{~s} ; 73.38^{\circ} \mathrm{N}, 54.62^{\circ} \mathrm{E}$

ISC $05 \mathrm{~h} 57 \mathrm{~m} 57.3 \mathrm{~s} ; 73.40^{\circ} \mathrm{N}, 54.57^{\circ} \mathrm{E}$

October 14, 1970

BI $05 \mathrm{~h} 59 \mathrm{~m} 59.8 \mathrm{~s} ; 73.35^{\circ} \mathrm{N}, 54.94^{\circ} \mathrm{E}$

ISC $05 \mathrm{~h} 59 \mathrm{~m} 57.3 \mathrm{~s} ; 73.31^{\circ} \mathrm{N}, 54.89^{\circ} \mathrm{E}$

Once the source parameters for the five explosions have been determined, the $S$ arrival times can readily be converted to absolute travel times. Table 1 lists all of the travel times and J-B residuals used in this study. Since three different source regions were used, it was expected that the data would separate naturally into three sets, each with a different base line. To examine this separation, the three data sets were plotted separately as residual times with respect to the computed J-B travel times (Figure 2).

The most immediate difference among the data sets is the much greater scatter in the Cannikin data. This finding was not unexpected, however. The local tectonic setting of the test site has been shown to introduce large azimuth- and distancedependent scatter into observed travel times [Davies and McKenzie, 1969; Davies and Julian. 1972]. Nevertheless, the basic trend of the residuals is consistent with that of the other data sets. However, because of this large scatter and a large base line shift, these data were not used in the final inversion.

The NTS data and the Novaya Zemlya data both show very low scatter, less than $\pm 1.3 \mathrm{~s}$. This is significantly less scatter than has previously been reported in $S$ wave studies [Kogan, 1960; Hales and Roberts, 1970; Robinson and Kovach, 1971]. This low scatter is a result of the stability and accuracy of our technique. In addition, we believe that this low scatter indicates that shear wave station corrections, which were not included in this study, are not as large or as important as earlier investigators have proposed [Doyle and Hales, 1967].

The NTS data set is much smaller than the Novaya Zemlya data set and does not significantly extend the distance range covered by the latter. In addition, the NTS data comprise only
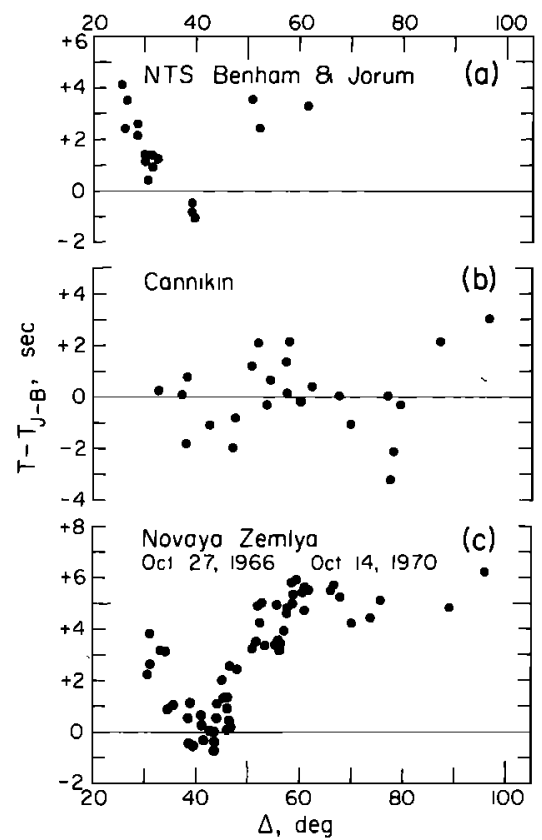

Fig. 2. Jeffreys-Bullen travel time residual plots of the observed data from $(a)$ the Nevada test site, $(b)$ Cannikin, and $(c)$ Novaya Zemlya.

a small range of azimuths and distances. For these reasons, it was not judged worthwhile to attempt to apply the necessary base line shift to the NTS data to make them compatible with the Novaya Zemlya data. Thus only the travel times from the two Soviet blasts were used to determine a velocity structure. It was still necessary, however, to determine accurate origin times for these explosions, since data from both events were combined. The Novaya Zemlya data also have the advantage of being a homogeneous data set from a nontectonic source region and with a wide range of azimuths and distances. This results in a more reliable average mantle sampling.

\section{Results}

These travel times were inverted to a lower mantle shear velocity structure by using as a starting model a modification of the Jordan and Anderson [1974] gross earth model B1. The data were inverted by using the linear inverse technique described by Jordan and Anderson [1974]. The model was modified to incorporate the upper mantle shear velocity structure

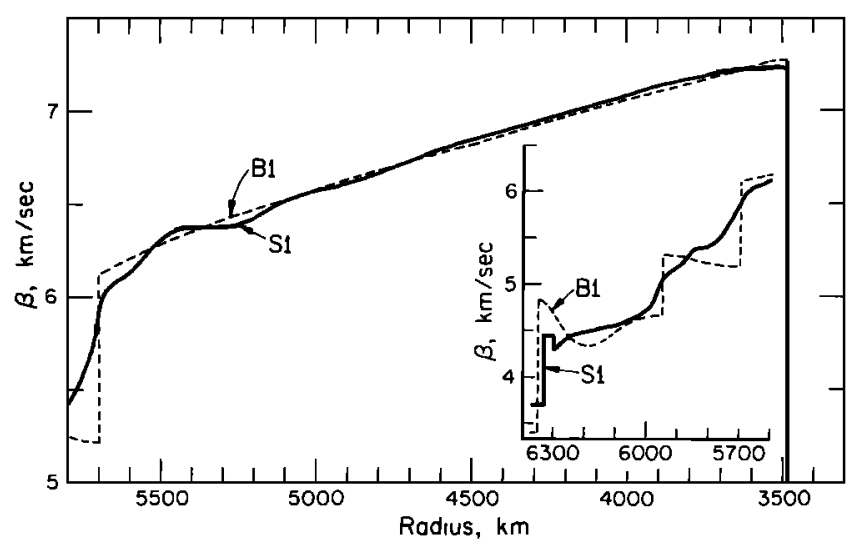

Fig. 3. The velocity structure of model SI (solid lines) for the lower mantle and (in the inset) for the upper mantle. Also shown for comparison in both regions is model BI [Jordan and Anderson. 1974] (dashed lines). 
TABLE 2. Shear Wave Velocity Structure (Model S1)

\begin{tabular}{|c|c|}
\hline Radius, $\mathrm{km}$ & Velocity, $\mathrm{km} / \mathrm{s}$ \\
\hline 6371 & 3.69 \\
\hline 6330 & 3.70 \\
\hline 6330 & 4.45 \\
\hline 6300 & 4.45 \\
\hline 6300 & 4.30 \\
\hline 6250 & 4.44 \\
\hline 6200 & 4.48 \\
\hline 6150 & 4.52 \\
\hline 6100 & 4.55 \\
\hline 6050 & 4.62 \\
\hline 6000 & 4.72 \\
\hline 5950 & 5.08 \\
\hline 5900 & 5.19 \\
\hline 5850 & 5.38 \\
\hline 5800 & 5.41 \\
\hline 5750 & 5.57 \\
\hline 5700 & 5.90 \\
\hline 5687 & 5.97 \\
\hline 5675 & 6.04 \\
\hline 5660 & 6.06 \\
\hline 5643 & 6.08 \\
\hline 5625 & 6.09 \\
\hline 5602 & 6.13 \\
\hline 5573 & 6.18 \\
\hline 5550 & 6.24 \\
\hline 5500 & 6.32 \\
\hline 5425 & 6.37 \\
\hline 5350 & 6.38 \\
\hline 5275 & 6.39 \\
\hline 5200 & 6.45 \\
\hline 5125 & 6.51 \\
\hline 5050 & 6.55 \\
\hline 4975 & 6.58 \\
\hline 4900 & 6.61 \\
\hline 4825 & 6.65 \\
\hline 4750 & 6.70 \\
\hline 4675 & 6.75 \\
\hline 4600 & 6.79 \\
\hline 4525 & 6.83 \\
\hline 4450 & 6.87 \\
\hline 4375 & 6.91 \\
\hline 4300 & 6.94 \\
\hline 4225 & 6.98 \\
\hline 4150 & 7.01 \\
\hline 4075 & 7.04 \\
\hline 4000 & 7.08 \\
\hline 3925 & 7.12 \\
\hline 3850 & 7.15 \\
\hline 3775 & 7.18 \\
\hline 3700 & 7.21 \\
\hline 3625 & 7.22 \\
\hline 3550 & 7.23 \\
\hline 3510 & 7.24 \\
\hline 3485 & 7.23 \\
\hline
\end{tabular}

determined by Helmberger and Engen [1974] for continental regions. Since our data represent ray paths through generally continental upper mantle regions, this model was expected to be most appropriate, and indeed, no base line shift was required in order to avoid any change in the Helmberger-Engen structure during the inversion. Since the ray paths involved had bottoming depths greater than $650 \mathrm{~km}$, the upper mantle structure serves primarily as a base line adjustment (although it will affect bottoming depths slightly), and one is relatively free to select the most convenient realistic structure.

The resulting velocity model, $\mathrm{Sl}$, is shown in Figure 3 (see also Table 2) along with the Jordan and Anderson [1974] model B1. As was mentioned above, we are concerned not with differences in structure above a radius of $5700 \mathrm{~km}$ (see Figure 3
TABLE 3. Travel Times for Surface Focus $S$

\begin{tabular}{|c|c|}
\hline Distance, deg & Time \\
\hline 30 & $11 \mathrm{~m} 13.5 \mathrm{~s}$ \\
\hline 32 & $11 \mathrm{~m} 44.3 \mathrm{~s}$ \\
\hline 34 & $12 \mathrm{~m} 14.7 \mathrm{~s}$ \\
\hline 36 & $12 \mathrm{~m} 44.9 \mathrm{~s}$ \\
\hline 38 & $13 \mathrm{~m} 15.0 \mathrm{~s}$ \\
\hline 40 & $13 \mathrm{~m} 44.7 \mathrm{~s}$ \\
\hline 42 & $14 \mathrm{~m} 14.4 \mathrm{~s}$ \\
\hline 44 & $14 \mathrm{~m} 44.0 \mathrm{~s}$ \\
\hline 46 & $15 \mathrm{~m} 13.4 \mathrm{~s}$ \\
\hline 48 & $15 \mathrm{~m} 42.8 \mathrm{~s}$ \\
\hline 50 & $16 \mathrm{~m} \mathrm{l1.9s}$ \\
\hline 52 & $16 \mathrm{~m} \mathrm{39.9s}$ \\
\hline 54 & $17 \mathrm{~m} \mathrm{07.3s}$ \\
\hline 56 & $17 \mathrm{~m} 34.4 \mathrm{~s}$ \\
\hline 58 & $18 \mathrm{~m} 01.1 \mathrm{~s}$ \\
\hline 60 & $18 \mathrm{~m} \mathrm{27.5s}$ \\
\hline 62 & $18 \mathrm{~m} \mathrm{53.4s}$ \\
\hline 64 & $19 \mathrm{~m} 18.8 \mathrm{~s}$ \\
\hline 66 & $19 \mathrm{~m} 43.3 \mathrm{~s}$ \\
\hline 68 & $20 \mathrm{~m} 07.3 \mathrm{~s}$ \\
\hline 70 & $20 \mathrm{~m} 30.8 \mathrm{~s}$ \\
\hline 72 & $20 \mathrm{~m} \mathrm{53.9s}$ \\
\hline 74 & $21 \mathrm{~m} 16.5 \mathrm{~s}$ \\
\hline 76 & $2 \operatorname{lm} 38.6 \mathrm{~s}$ \\
\hline 78 & $22 \mathrm{~m} 00.3 \mathrm{~s}$ \\
\hline 80 & $22 \mathrm{~m} 21.5 \mathrm{~s}$ \\
\hline 82 & $22 \mathrm{~m} 42.2 \mathrm{~s}$ \\
\hline 84 & $23 \mathrm{~m} 02.5 \mathrm{~s}$ \\
\hline 86 & $23 \mathrm{~m} 22.2 \mathrm{~s}$ \\
\hline 88 & $23 \mathrm{~m} 41.3 \mathrm{~s}$ \\
\hline 90 & $24 \mathrm{~m} 00.0 \mathrm{~s}$ \\
\hline 92 & $24 \mathrm{~m} 18.3 \mathrm{~s}$ \\
\hline 94 & $24 \mathrm{~m} 36.2 \mathrm{~s}$ \\
\hline 96 & $24 \mathrm{~m} 53.9 \mathrm{~s}$ \\
\hline 98 & $25 \mathrm{~m} 11.4 \mathrm{~s}$ \\
\hline 100 & $25 \mathrm{~m} 28.6 \mathrm{~s}$ \\
\hline
\end{tabular}

inset) but only with the velocity structure below that point. Model BI has a very smooth shear wave gradient throughout the entire lower mantle. The newer model, SI, however, has substantial structure in this region, particularly between radii of 5100 and $5700 \mathrm{~km}$. Another prominent feature of this new model is a flattening of the velocity gradient in the bottom 200 $\mathrm{km}$ of the mantle, although this region is not well constrained by the data set employed.

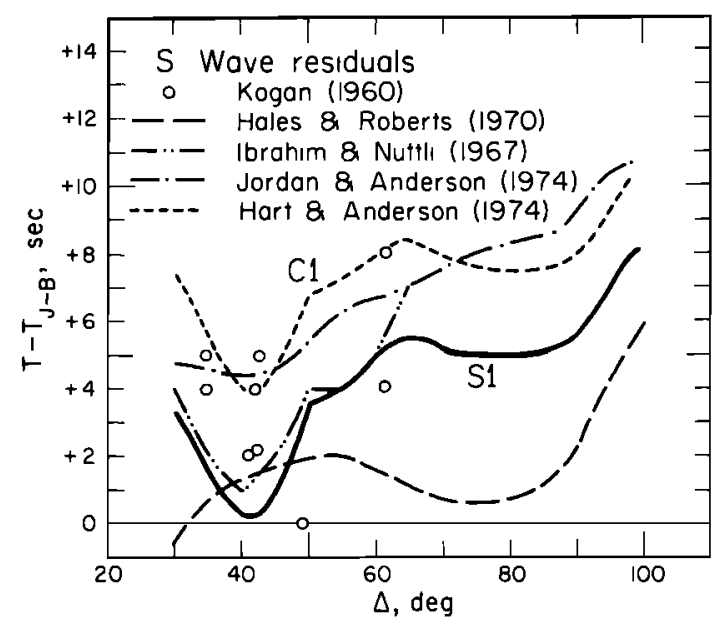

Fig. 4. Jeffreys-Bullen travel time residual curves for model SI, model B 1 [Jordan and Anderson, 1974], model Cl [Hart and Anderson, 1974], and the models of Hales and Roberts [1970], Ibrahim and Nutli [1967], and Kogan [1960]. 


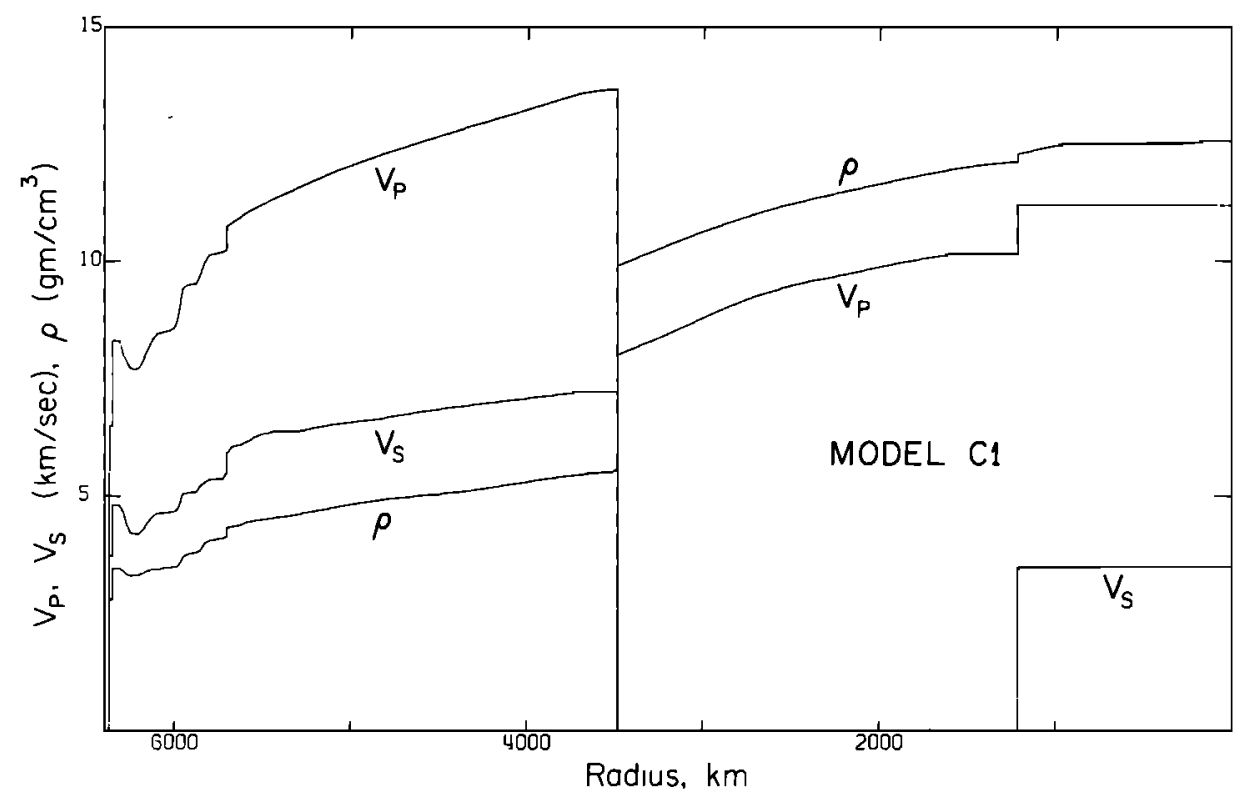

Fig. 5. The velocity and density structure of model $\mathrm{Cl}$.

The shear wave travel time curve is similarly more complex. Table 3 lists the surface focus travel times for SI, but a better picture of the travel times for this model can be obtained by considering the $\mathrm{S} 1$ time residuals in relation to the $\mathrm{J}-\mathrm{B}$ times (Figure 4). The most prominent feature of the residual curve is the deep minimum at roughly $40^{\circ}$. This feature of the shear wave travel time curve was also observed by Ibrahim and Nuttli [1967] and corresponds to a sharp velocity increase near a radius of $5500 \mathrm{~km}$. However, beyond a distance of $60^{\circ}$ the $S 1$ residual curve flattens out at roughly $+5.0 \mathrm{~s}$ until at $90^{\circ}$ the residuals sharply increase. This behavior is similar to the results of Hales and Roberts [1970] except for about a 4.5-s base line shift. Both the S1 model and Ibrahim and Nuttli [1967] predict a definite change in $d t / d \Delta$ at about $50^{\circ}$. (See also the paper by Hales and Roberts [1970].)

By using only distances greater than $30^{\circ}$, all of the rays have nearly vertical paths through the upper mantle. Hence since essentially all of the stations used are continental, the effects of major lateral inhomogeneities in the upper mantle should appear primarily as base line shifts between the three data sets. Indeed, there is a shift toward faster times from the Novaya Zemlya data to the NTS data and especially to the Cannikin data. This finding correlates with the trend toward increasing tectonic activity in the three regions. Furthermore, since the inversion data set covers a wide range of azimuths, the resultant model, S1, should represent a gross earth, lower mantle, shear velocity structure. To test that hypothesis, Hart and Anderson [1974] used the SI lower mantle structure in a study of the earth's free oscillations. The Helmberger-Engen upper mantle structure was modified to include a well-developed lithospheric lid and a low-velocity zone, and consistent compressional velocity and density structures for the whole earth were constructed. This model was then inverted, following the technique of Jordan [1973], with some 180 modes to obtain model Cl [Hart and Anderson, 1974]. Cl (Figure 5) included only extremely small changes in the lower mantle shear velocity structure, as can be seen by comparing the J-B travel time residuals for the two models in Figure 4. The two curves are almost identical except for a 3-s base line shift. This base line shift is consistent with differences observed by Sipkin and Jor- dan [1974]. Yet $\mathrm{Cl}$ was extremely effective in fitting all of the fundamental spheroidal and toroidal modes of the earth as well as a large number of overtones. Further work is now under way [Anderson et al., 1975] to include all available overtone data into a successor to model $\mathrm{Cl}$.

\section{Conclusions}

A new technique utilizing theoretical wave forms of the $p S$ phase from explosions has been developed for the precise determination of shear wave travel times. The application of this technique to shear waves from five large nuclear explosions has given a $p S$ travel time data set with very little scatter. This data set permitted a reliable inversion to a lower mantle shear velocity structure. This velocity structure not only reproduces the observed travel times but also is an appropriate gross earth structure for free oscillation studies. This velocity structure, then, should serve as a useful basis for the study of lateral variations and of the mineralogical composition in the lower mantle.

Acknowledgments. I would like to thank Don L. Anderson for his many helpful comments and suggestions throughout this study and for critically reading this manuscript. I would also like to thank Donald V. Helmberger for his suggestions and aid and Thomas H. Jordan and Bruce R. Julian for their comments and the use of their computer programs. I thank the National Science Foundation and the Beno Gutenberg Fellowship Fund for graduale fellowship support. This research was supported by the Advanced Research Projects Agency of the Department of Defense and was monitored by the Air Force Office of Scientific Research under contract F44620-72-C-0078. Contribution 2580 of the Division of Geological and Planetary Sciences, California Institute of Technology, Pasadena.

\section{REFERENCES}

Anderson, D. L., R. S. Hart, and T. H. Jordan, An earth model based on free oscillations and body waves, submitted to J. Geophys. Res., 1975.

Bullen, K. E., A suggested new 'seismological' latitude, Mon. Notic. Roy. Astron. Soc., 4, geophys. suppl., 158, 1937.

Davies, D., and B. R. Julian, A study of short period $P$-waves from Longshot, Geophys. J. Roy. Astron. Soc., 29, 185, 1972.

Davies, D., and D. P. McKenzie, Seismic travel times and plates, Geophys. J. Roy. Astron. Soc., 18, 51, 1969. 
Doyle, H. A., and A. L. Hales, An analysis of the travel times of $S$ waves to North American stations in the distance range $28^{\circ}$ to $82^{\circ}$, Bull. Seismol. Soc. Amer., 57, 761, 1967.

Dziewonsk1, A., and F. Gilbert, Observations of normal modes from 84 recordings of the Alaskan earthquake of 1964 March 28 . Geophys. J. Roy. Astron. Soc., 27, 393, 1972.

Engdahl, E. R., Seismic effects of the Milrow and Cannikin nuclear explosions, Bull. Setsmol. Soc. Amer., 62, 1411, 1972.

Hales, A. L., and J. L. Roberts, Shear velocities in the lower mantle and the radius of the core, Bull. Seismol. Soc. Amer., 60, 1427, 1970.

Hamilton, R. M., and J. H. Healy, Aftershocks of the Benham nuclear explosion, Bull. Seismol. Soc. Amer., 59, 2271, 1969.

Hart, R. S., and D. L. Anderson, Velocity and density structure of the earth, paper presented at 46th Annual Meeting, East. Sect., Seismol. Soc. of Amer., Harvard Univ., Cambridge, Mass., Oct. 10-11, 1974.

Haskell, N. A., Analytic approxımation for the elastıc radiation from a contained underground explosion, J. Geophys. Res., 72, 2582, 1967. Helmberger, D. V, and G. R. Engen, Upper mantle shear structure, $J$. Geophys. Res., 79, 4017, 1974.

Helmberger, D. V., and D. G. Harkrider, Seismic source descriptions of underground explosions and a depth discriminate, Geophys. J. Roy. Astron. Soc., 3I, 45, 1972.

Herrin, E., et al., 1968 seismological tables for $P$ phases, Bull. Seismol. Soc Amer., 58, 1193, 1968.

Ibrahim, A. K., and.O. W. Nuttli, Travel-time curves and upper mantle structure from long period $S$ waves, Bull. Seismol. Soc. Amer., 57, 1063, 1967.

Jordan, T. H., Estımation of the radial variation of seismic velocities and the density of the earth, Ph.D. thesis, Calif. Inst. of Technol. Pasadena, 1973.

Jordan, T. H., and D. L. Anderson, Earth structure from free oscillations and travel times, Geophys. J. Roy. Astron. Soc., 36, 411, 1974.

Kogan, S. D., Travel times of longitudinal and transverse waves calculated from data on nuclear explosions made in the region of the Marshall Islands, Izv. Acad. Sci. USSR Phys. Solid Earth, Engl. Transl., no. 3, 246, 1960.

Nutılı, O. W., Travel times and amplitudes of $S$ waves from nuclear explosions in Nevada, Bull. Seismol. Soc. Amer., 59, 385, 1969

Robinson, R., and R. L. Kovach, Shear wave velocities in the earth's mantle, Phys. Earth Planet. Interiors, 5, 30, 1971.

Sipkın, S. A., and T. H. Jordan, The base line difference between continents and oceans (abstract), Eos Trans. $A G U, 55,350,1974$.

Stauder, W., Smaller aftershocks of the Benham nuclear explosion, Bull. Seismol. Soc. Amer., 61, 417, 1971.

(Received February 14, 1975;

revised July 28, 1975;

accepted July 31,1975 .) 